Rio-Durham (NC)-Berlim: um diário de idéias. Fábio Akcelrud Durão (Campinas: UNICAMP/IEL/Setor de Publicações, 2008)

\title{
TEORIA E ASCESE COTIDIANA
}

O livro do professor do Departamento de Teoria Literária da Unicamp, Fábio Durão, é um acontecimento único na produção editorial da teoria no Brasil. Trata-se de um "diário de idéias" feito de fragmentos aforismáticos que discorre de maneira muito pessoal sobre a situação da teoria nos três países - Brasil, EUA e Alemanha - que fizeram parte da formação do autor; por outro lado, aborda de maneira muito teórica experiências pessoais e cotidianas. É na duplicidade constitutiva da proposta que vamos nos adentrar.

Os fragmentos focam diferentes insights da relação de um personagem teórico com dois ambientes aparentemente estranhos: a universidade e o cotidiano. O desafio é, precisamente, pensar um com os olhos do outro, de modo que, recolhendo o melhor da teoria (a virulência crítica) e do cotidiano (a delimitação prática), haja de certo modo uma correção mútua do pior e potencialização mútua do melhor. $\mathrm{Na}$ teoria, o problema está na pletora de objetos mapeados e fabricação de modos de interpretação infinitos que neutralizam um trabalho do pensamento feito de irrupçôes, elaboração e pausas - momentos de silêncio. Essa questão aparece no interior de teorias atuais (desconstrução, estudos culturais), bem como na dimensão da prática universitária: excesso competitivo de estudo, iconização do nome dos filósofos, economia das citações, classificação de teorias como modos de leitura da realidade, métodos de ensino da literatura (p. 14, 21, 41). No cotidiano, a dificuldade está em lidar com a estrutura perversa do sistema de nos levar a vivências já preparadas, um consumo de modos de viver prévios. São analisados vários exemplos: os 100 sabores da loja de sorvete (p. 24, fragmento 19), as janelas dos apartamentos americanos (p. 25, fragmento 20), a visita e foto turística obsessiva por todos os lugares (p. 26-27, fragmento 22), o trabalho da audição nas salas de concertos (p. 24, fragmento 18) etc. A reflexão do cotidiano se desdobra em tornar o olhar estrangeiro uma forma metodológica de crítica de diferentes culturas, cotejando entre si EUA, Brasil e Alemanha, algo que poderíamos chamar de critica da cultura comparada. 
Por outro lado, o olhar desconfiado frente ao cotidiano não poupa o próprio cotidiano da universidade: pensa-se o quanto a vida intelectual está aprisionada em práticas estandardizadas e o quanto a reflexão sobre o seu cotidiano ataca diretamente a reificação do conteúdo produzido. Em ambos os casos, o personagem teórico dos fragmentos elenca os modos de reprodução da vida falsificada no mundo administrado em tempos pós-modernos e se coloca em questão, em primeira pessoa, na prática mais pessoal e inalienável (em pleno conflito com a inoculação íntima da alienação), sobre como agir e reagir, como avaliar e apreciar o que advém da imediaticidade do cotidiano.

Contra as diversas formas de ascese obsessiva que o sistema impõe (criando modelos de conduta, verdadeiros personagens típicos da cultura, como o do playboy brasileiro) (p. 45-46, fragmento 49), o ousado e modesto teórico não deixa de, ao procurar surpreender teoricamente um campo de problemas do cotidiano feito para se conservar impensado, praticar uma outra ascese. Trata-se de uma ascese da resistência (ou na expressão do esclarecedor prefácio de Marcus Siscar, "postura de resistência") (p. 8) contra vivências imediatas impostas pelo sistema de conduta do estado falso, contra a aniquilação da experiência feita pelo controle disciplinar do espaço-tempo de trabalho e lazer; trata-se, enfim, de suspender o fluxo de imposições imediatas com a mediação de uma teorização do cotidiano. Isto é, nada mais ascético, mesmo que tal suspensão seja, em certos aspectos, anti-laboral, feita na mesa de bar, contrária à abundância de referências, ferramentas, possibilidades infinitas. A ascese moderna da teorização do cotidiano é contra, no fundo, pseudo-asceses que obedecem a modelos midiáticos e institucionais disciplinares, mesmo quando tais modelos se reproduzem no lugar que mais deveria questioná-los: na universidade pós-moderna, no próprio modo de vida dos críticos da reificação.

Daí a relevância, aqui, de nossa resenha dever abrir um parêntese para a diferença entre ascese e disciplina. A disciplina é imposta por educadores e instituições para a obtenção de êxitos em avaliaçōes (provas, concursos), a ascese é construída por um sujeito singular para realização de um desejo absoluto (principalmente no caso da mística) por meio da renúncia a prazeres mundanos. A ascese tradicional de monges foi feita com base numa instituição que fomenta lugares de recolhimento, como o mosteiro, a disciplina tradicional se dá sempre no interior de uma instituição que 
controla o espaço-tempo do indivíduo - escola, hospital, prisão. Contudo, podemos pensar que, atualmente, com a informalização das atividades trabalhistas, o controle vigilante ao ar livre de cada movimento dos cidadãos, a passividade forçada da televisão e a atividade falsa dos jogos e da navegação virtual, entre outros fenômenos, o regime disciplinar se torna onipresente. A ascese, hoje, é em grande parte uma radicalização da disciplina: a anorexia das patricinhas, os workaholics, o planejamento sufocante dos turistas com seu roteiro, tudo isso é uma forma de, por meio de sacrifício dos prazeres do ócio, obter as virtudes do sistema: beleza, dinheiro, sucesso, signos de poder. Logo, a prática ascética é, nesses casos, nada mais do que o desdobramento exagerado da disciplina atual, em harmonia com o conceito de ascese protestante dos primeiros capitalistas de Weber, sendo dela a perfeita herdeira. Quando Fabio Durão pensa, nos EUA, o quanto o gordo se tornou proletário e o jovem marombeiro frequentador de academia, o burguês atual (p. 20, fragmento 13), está se referindo, a nosso ver, a uma das metamorfoses recentes da ascese burguesa.

Contudo, se o mundo é cada vez mais disciplinar e suscita asceses heterônomas, é necessário um grande esforço - ascético - para resistir não só à reprodução prática da disciplina imposta pela falsificação da existência, mas principalmente aos valores dessa falsificação. Isso só pode ser feito com a ascese singular do teórico crítico, que insere mediações do exercício crítico de pensar, suspensóes, pausas, sedimentaçôes. É uma ascese estética, hedonista, por um lado, para abrir espaço ao potencial crítico do ócio (que só é ócio do ponto de vista do mero cálculo das horas de trabalho, porém na verdade é outro tipo de trabalho ininterrupto, como provam as especulaçôes do nosso personagem teórico pensando no vendedor turco na Alemanha) (p. 56-57, fragmento 64); e ainda mais trabalhosa, por outro, por demandar um esforço de recusa monstruoso diante da facilidade imediata.

Por isso, consideramos esse um livro genuinamente ascético. Ele nos apresenta uma estimável ascese teórica, e nos convida, sem dúvida, a praticar uma outra, contribui decisivamente para a ascese singular de cada um, pois asceses explícitas na escrita teórica servem para entrarem em diálogo, dialética. Nesse sentido, o livro abre uma perspectiva riquíssima - pouco percebida em outros livros que procuraram uma reflexão parecida, como Minima moralia de Adorno, Cool memories de Baudrillard, Rua de mão única de Ben- 
jamin -: tornar a teoria menos reprodutora de si mesma, por mais que ela deva se distanciar da prática, e mais prática, por mais que sua imanência seja insolúvel. Mas em que sentido a teoria deveria tornar-se mais prática, se justamente ela deve lutar contra a resistência à teoria das visões utilitaristas? No fato de que, justamente, ela pensou pouco um tipo de prática que a literatura pensou muito: a cotidiana, em forma de diário, na primeira pessoa; encarar a pobreza e a riqueza da experiência individual. É uma forma de a teoria ser mais literária, ainda que o livro sabiamente evite narrativas pessoais, não fale de amores nem de família, selecionando, no limite, apenas pequenos momentos de conversas com amigos para decolar o vôo de reflexões ao rés do chão. $\mathrm{O}$ objeto da teorização do cotidiano impele ao enfoque pessoal, mas na medida certa, de modo a focar fenômenos culturais gerais, que, entretanto, atingem intimamente a vida do dia a dia de todos.

A forma do diário, enfim, aproxima-se menos da autobiografia, demasiadamente individual, do que de textos ascéticos tradicionais, que observam o cotidiano com vistas a criticá-lo e transformá-lo com o olhar pessoal e exercícios específicos; mas é claro que a semelhança para por aí, pois o pensamento é laico e o objetivo não é religioso. Ainda assim, quando recusamos a semelhança superficial, insistimos na semelhança profunda (vinda da mais extrema diferença histórica) de uma resistência mediante certas renúncias: na ascese tradicional, aos prazeres mundanos, na ascese teórica, aos gozos da vida falsificada. Assim como para o asceta tradicional o mundo é pecado, para o teórico crítico, o mundo é regido pelo estado falso, e uma experiência que possa sair daí, na medida do possível, só se dá no deserto solitário da teoria sem concessões ao pecado capital de entregar a vida aos ditames da maioria. O conceito de prática aqui, portanto, não é privilegiadamente político, mas ligado ao âmbito da experiência individual, não é só a micro-política, é a micro-existência de viver a minúcia profana. É aí, a nosso ver, que a teoria pode e deve tornar-se mais prática: em pensar e experimentar uma prática impensada e mal praticada, precisamente, pela teoria e mesmo pela vida universitária.

Com isso, o teórico não se furta aos prazeres da indústria cultural, não é tão chato assim, mas vai surpreender a lidar com a imediaticidade precisamente lá onde ela mais está nos invadindo, conquistando, assim, territórios que os papers e a codificação da forma nas revistas acadêmicas insistem em não tocar (para uma análise de 
uma das formas de codificação do artigo científico, "Sobre o conceito de X em Y", ver p. 42, fragmento 45). Quando a teoria se torna mais prática, intrometendo-se na dimensão da objetividade mais intransitável e impensada pela filosofia (ainda que Montaigne, pré-românticos alemães e muitos outros desmintam o muro estabelecido pelos sistemas filosóficos e sejam sempre mal aproveitados), a teoria se mostra mais digna de seu nome. Se a forma ensaística foi parcialmente codificada pelo artigo universitário, mesmo assim os fragmentos do livro expõem o grau de distância que o artigo acadêmico se encontra de uma crítica que atinja hábitos tornados regra de conduta na concretude da vivência diária.

Por isso e muito mais, o livro de Fábio Durão dá um sopro renovador na teoria literária brasileira. Lembro que o Brasil produz trabalho de qualidade na área de teoria geralmente quando aborda objetos de estudo nacionais, restringindo o alcance da teorização ao seu território, daí o fato de a sociologia da literatura ter dados frutos mais rentáveis. Contudo, falta uma simultânea ousadia e consistência para pensar também simultaneamente o aqui e o ali e refletir sobre a teoria, hoje globalizada, sem cair em classificações escolares, métodos fixos de interpretação ou mera reprodução de escolas importadas. Durão realiza essa difícil tarefa da forma (no duplo sentido) mais modesta. Em primeira pessoa, trata até mesmo o Brasil como lá, enquanto está na Alemanha e nos EUA, mas justamente nesse momento a tradição não só de pensar o Brasil como do exercício autônomo de pensar dos brasileiros, feito precisamente sob a pressão do deslocamento do exílio, está dando seu mais novo salto.

\section{Eduardo Guerreiro Brito Losso (UFRRJ)}

